\title{
Investigation of thermochemical process of coal particle packed bed reactions for the development of UCG
}

\author{
Tata Sutardi $^{1,2} \cdot$ Linwei Wang $^{1,3} \cdot$ Nader Karimi $^{4} \cdot$ Manosh C. Paul $^{1}$ (I)
}

Received: 30 March 2020/Revised: 9 June 2020/Accepted: 24 August 2020/Published online: 3 September 2020

(C) The Author(s) 2020

\begin{abstract}
In this study, a packed bed reactor was developed to investigate the gasification process of coal particles. The effects of coal particle size and heater temperature of reactor were examined to identify the thermochemical processes through the packed bed. Three different coal samples with varying size, named as A, B, and C, are used, and the experimental results show that the packed bed with smaller coal size has higher temperature, reaching $624{ }^{\circ} \mathrm{C}, 582{ }^{\circ} \mathrm{C}$, and $569^{\circ} \mathrm{C}$ for coal $\mathrm{A}, \mathrm{B}$, and $\mathrm{C}$, respectively. In the case of $\mathrm{CO}$ formation, the smaller particle size has greater products in the unit of mole fraction over the area of generation. However, the variation in the porosity of the packed bed due to different coal particle sizes affects the reactions through the oxygen access. Consequently, the $\mathrm{CO}$ formation is least from the coal packed bed formed by the smallest particle size A. A second test with the temperature variations shows that the higher heater temperature promotes the chemical reactions, resulting in the increased gas products. The findings indicate the important role of coal seam porosity in underground coal gasification application, as well as temperature to promote the syngas productions.
\end{abstract}

Keywords Thermochemical process · Particle packed bed · Coal particle gasification · Gas products · Underground coal gasification (UCG)

\section{Introduction}

The Survey of Energy Resources was published in 2016, which estimated that the world coal reserves are approximately 890 billion tonnes (World Energy Council 2013),

Manosh C. Paul

Manosh.Paul@glasgow.ac.uk

1 Systems, Power and Energy Research Division, James Watt School of Engineering, University of Glasgow, Glasgow G12 8QQ, UK

2 The Agency for Assessment and Application of Technology (BPPT), Jakarta, Republic of Indonesia

3 Centre for Renewable Energy Systems Technologies (CREST), Wolfson School of Mechanical, Electrical and Manufacturing Engineering, Loughborough University, Leicestershire LE11 3TU, UK

4 School of Engineering and Materials Science, Queen Mary University of London, London 1E 4NS, UK and there are another greater resources, which are not mineable in deep underground. Underground coal gasification (UCG) technology is, therefore, an option to utilise this type of coal reserve (Yang et al. 2014; Bhutto et al. 2013). Through this process, coal as a type of fuel can be extracted in a gas phase, which is known as synthesis gas or syngas.

The study of UCG has been carried out for many years, through laboratory scale experiment to pilot plant demonstration, as well as through computational simulation (Khan et al. 2015). However, the challenges are still there, which need to be overcome for a successful development and deployment of a UCG technology (Walker 2007). Some of the notable challenges for UCG development include obtaining better quality syngas with higher heating values, high thermal efficiency, high process efficiency, good control on the combustion front, as well as handling the depth of the coal, and gas clean-up (Gunn 1977). 
This study focuses on the investigation of thermochemical behaviour of coal reactions for understanding the processes to occur in a UCG application. The study began with the aim of improving the reaction mechanisms of coal gasification through a model simulation conducted recently by Sutardi et al. (2018a, b). Based on the literature, three different models for the development of UCG were presented-packed bed model, channel model, and coal slab model (Khan et al. 2015; Sarraf Shirazi et al. 2013).

The oldest model of UCG is still believed to a packed bed reactor (Khan et al. 2015). The consideration of this model primarily originated from the concept of Higgins (1972), who considered the creation of a permeable zone between two boreholes of UCG process (Thorsness and Rosza 1976; Uppal et al. 2014). The packed bed model assumes that coal gasification occurs in highly permeable porous media with a stationary coal bed which is consumed over time (Khadse et al. 2006). However, these models have limitations in providing the radiation mechanisms as it occurs in the gasification reactions (Khan et al. 2015). In addition, Winslow (1977) pointed out this method requires a fine grid resolution in the vicinity of the reaction front, thus it limits the applicability to field-scale trials.

The channel model developed in the first decades of UCG modelling (Khan et al. 2015) assumes that coal is gasified only at the perimeter of the expanding permeable channel (Gregg and Edgar 1978). The UCG process is represented by an expanding channel where two distinct zones of coal seam separated and form a channel (Batenburg et al. 1994; Kuyper et al. 1996). The basic concept behind this approach is that air/oxygen flows down to the central channel. The oxygen diffuses through the boundary layer to the solid surface and reacts. The hot combustion gases diffuse back through the boundary layer to the channel (Gunn and Krantz 1987), and the channel model is more useful for analysing sweep efficiency. However, the channel model has limitation in presenting drying and pyrolysis mechanisms which are very important reactions in gasification.

On the other hand, the coal slab model for UCG coal seam describes the process by movement of various defined regions in a coal slab (Khan et al. 2015). These regions usually include the gas, ash layer, char region, dried coal and virgin coal. The existence of different regions is caused by the slow heating rate of UCG. At a very high heating rate, there is a possibility of the coincidence of a drying front with a combustion front (Tsang 1980). However, this model is yet to be validated using UCG trial data and has limitation in presenting the mass conservation procedures to describe the cavity formation (Khan et al. 2015).

Without doubt, each model has a contribution on the UCG modelling development. However, they still have a limitation in providing a set of particular reaction kinetics for gasification processes (Khan et al. 2015). Therefore, further study is needed (Harish et al. 2014; Yang et al. 2014), and the coal particle modelling approach was taken as an initial model development (Sutardi et al. 2018a, b; Sielke and Gorin 1955; Sutardi 2019; Bhutto et al. 2013). The method considered coal as a multi-phase-component of solid-gas (Khatami et al. 2012; Levendis et al. 2011), and with this approach the whole reactions of gasification mechanisms were presented in the simulation.

Earlier, an initial development of a coal particle gasification model has been performed through computational simulations (Sutardi et al. 2017, 2018a, b; Wang et al. 2018, 2019). The result has clarified the behaviour of thermochemical process of gasification reaction mechanisms. Further assessment is proposed, and the study on coal particle gasification for UCG application, presented in this paper, is implemented through a particle packed bed reactor. This work is necessary to validate and evaluate the model of coal particle gasification in the previous study. A number of coal particles packed and collected into a bed to form a coal block. The coal block is then set up for a reaction process to investigate the gasification behaviour. This paper initiates the study of coal particle block reactions in a packed bed, through experimental investigation. The paper then focuses on the investigation of thermochemical behaviour, with the measured thermal and gas products and how they are influenced by the alternation of the process's operating and boundary conditions. Comparison of findings between the results of model simulation and experimental development will be established to provide with the necessary information for the UCG development.

\section{Experimental set-up}

\subsection{Equipment and instrumentations}

A schematic view of the packed bed experiment developed in this study is shown in Fig. 1. The coal particles were clustered together to form a packed bed that was placed to the heater closely. The hot gas flows through the bed where the reaction process happens.

The schematic process of the installation for the experimental setup can be seen in Fig. 2 .

The main rig, as the gasification reactor, was made from mild steel which provides formability properties in the machining process but still resists a high temperature. The inner dimension of the reactor was $500 \mathrm{~mm} \times 200$ $\mathrm{mm} \times 25 \mathrm{~mm}$ (length $\times$ width $\times$ height). The rig was covered by a quartz glass to make the coal bed reactions observable. Air was supplied through the two inlet accesses, and another two outlets were provided for the gas 


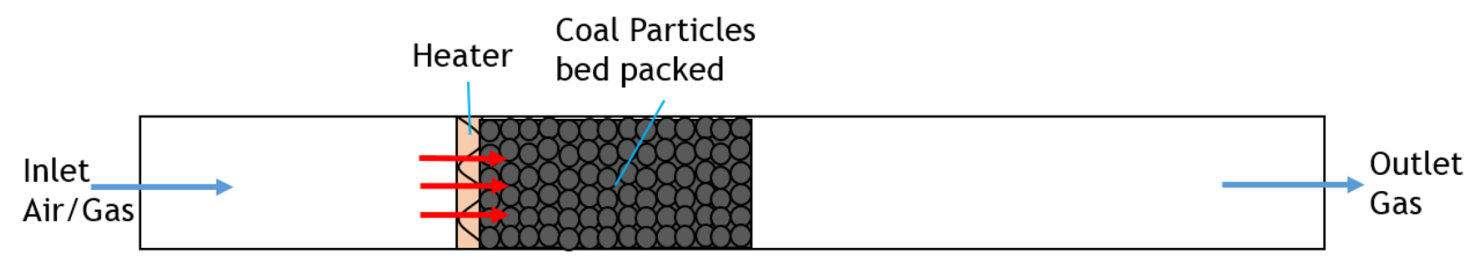

Fig. 1 Illustration of coal particle bed packed in a reactor

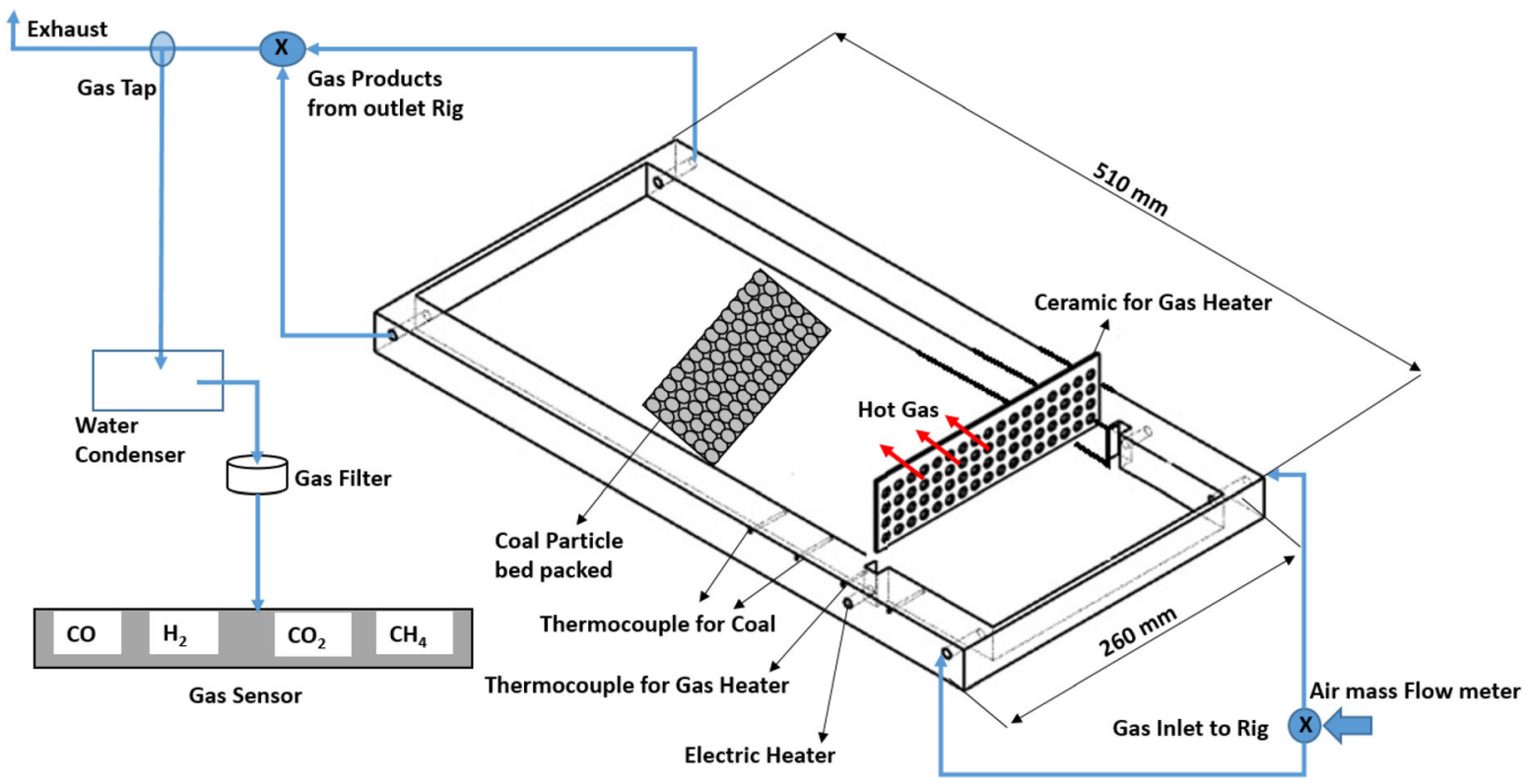

Fig. 2 Schematic diagram for experiments

products to flow out of the reactor. The injected air was controlled by the gas mass flow meter and was set within 0-20 slpm in the experiments. The unit measured was in a standard condition of gas (i.e. $1 \mathrm{~atm}$ and $25^{\circ} \mathrm{C}$ ). The valve of the air flowrate control was set as a single direction valve to avoid any back pressure because of the temperature differences.

An electric heater was provided with a wire heater and twisted in the ceramic honeycomb plates. The honeycomb structure allowed the air to be heated as it goes through. The wire has a resistance of $\sim 3.9 \Omega / \mathrm{m}$ with a length approximately of $1 \mathrm{~m}$ and supplied with DC current of $\sim 7.5 \mathrm{~A}$. The experiment was performed with two electric wire-heaters in order to achieve air temperatures up to $\sim 400{ }^{\circ} \mathrm{C}$.

Seven channels of thermocouple type K were used and placed in the coal bed area to record the temperature propagation inside the packed particles. Channel 1 aimed to measure the heated air at the inlet of the reactor or the coal packed bed. Channels 2, 3 and 4 were used to measure the lower side of the coal bed, and channels 5, 6, and 7 were for the upper side of the coal bed area. The position of thermocouples in the packed bed reactor was also shown in
Fig. 3. The coal reactions were identified with the heat propagation over the time. Therefore, the sensor was put along the bed to record and obtain the temperature profile. The heat propagation was expected to be in line with the gas flow. It started at the coal near to the heater, identified with channel 1 and then continues to channels 2 and 5 and so on. All the data of temperature measurements were logged through a hub and recorded in the computer's memory.

The current investigation focuses on the char performance reactions, and the gas sensors were set up to analysis the gas products with carbon basis $\left(\mathrm{CO}_{2}, \mathrm{CO}\right.$, and $\left.\mathrm{CH}_{4}\right)$ from the char or carbon reactions. Here, an $\mathrm{O}_{2}$ sensor was used to identify the availability of the excess air of reactions, and the specification of all the gas sensors used in the experiment can be seen in Table 1 .

In order to prevent the sensor contact with water, the water trap was provided. It was consisted of the glass container with the ice bath, and they work as a condenser system. 


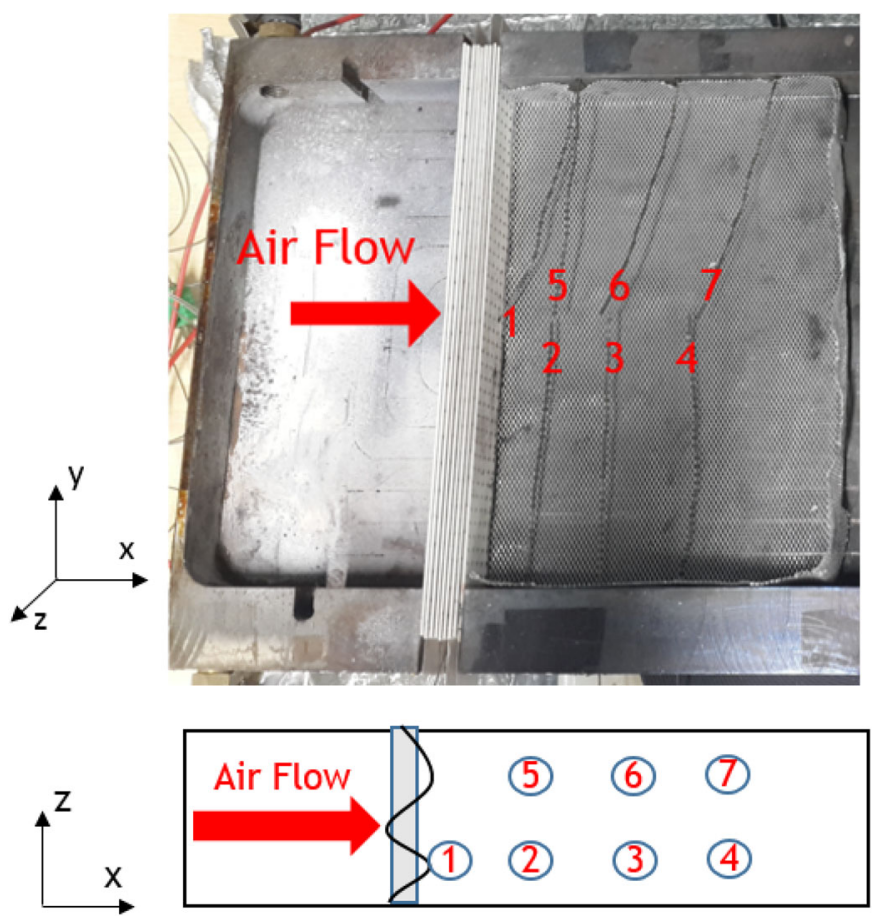

Fig. 3 Thermocouples position in the coal bed area from top and side views

Table 1 Gas sensor specification

\begin{tabular}{ll}
\hline Parameter & Range of measurements $(\%)$ \\
\hline $\mathrm{CO}_{2}$ & $0-100$ \\
$\mathrm{CO}$ & $0-100$ \\
$\mathrm{CH}_{4}$ & $0-30$ \\
$\mathrm{O}_{2}$ & $0-25$ \\
\hline
\end{tabular}

\subsection{Coal particle properties and preparation}

The fuel sample used in the experiments was charcoals in which the dominant element is carbon. The volatile matters in coal were not considered in this experiment, because the focus was on the char reactions as in the model simulation showed its important effect on the gasification reactions (Sutardi et al. 2018b).

For the investigation purposes, the charcoal particle is classified into three different sizes based on the screening dimension, and they are named as Coal A, B, and C. The ID of $\mathrm{A}, \mathrm{B}$, and $\mathrm{C}$ have been identified for the coal particles that could pass the screening with a size of $1 \mathrm{~mm} \times 1 \mathrm{~mm}$; $2 \mathrm{~mm} \times 2 \mathrm{~mm}$; and $4 \mathrm{~mm} \times 4 \mathrm{~mm}$, respectively. The detail information of chemical and physical properties of the charcoal can be seen in Table 2. The chemical properties presents the ultimate analysis' results of the fuel, and meanwhile, the physical property of charcoal sample for
Table 2 The chemical and physical properties of charcoal

\begin{tabular}{|c|c|c|}
\hline \multicolumn{3}{|c|}{ Chemical composition for coal A, B, and C } \\
\hline \multicolumn{2}{|l|}{ Elements } & Composition (\%) \\
\hline \multicolumn{2}{|l|}{ Carbon } & 66.21 \\
\hline \multicolumn{2}{|c|}{ Hydrogen } & 3.00 \\
\hline \multicolumn{2}{|l|}{ Nitrogen } & 1.04 \\
\hline \multicolumn{2}{|c|}{ Oxygen, (by difference) } & 29.75 \\
\hline \multicolumn{3}{|c|}{ Physical properties (coal size) } \\
\hline Coal ID & Screen size & Status \\
\hline Coal A & $1 \mathrm{~mm} \times 1 \mathrm{~mm}$ & Passed \\
\hline \multirow[t]{2}{*}{ Coal B } & $1 \mathrm{~mm} \times 1 \mathrm{~mm}$ & Not passed \\
\hline & $2 \mathrm{~mm} \times 2 \mathrm{~mm}$ & Passed \\
\hline \multirow[t]{2}{*}{ Coal C } & $2 \mathrm{~mm} \times 2 \mathrm{~mm}$ & Not passed \\
\hline & $4 \mathrm{~mm} \times 4 \mathrm{~mm}$ & Passed \\
\hline
\end{tabular}

each size, as described in Table 2, visually can be seen in Fig. 4.

Figure 4 gives the morphology of the coal packed beds A to $\mathrm{C}$ with different particle sizes. In the experiment, the amount of mass used was 120 grams for each test and it fully covers the bed volume up to thermocouple 3 and 6 . Sensor temperature number 4 and 7 were not fully covered with the coal particles and therefore they can be used to measure the temperature of gas outlet or additional heater. 


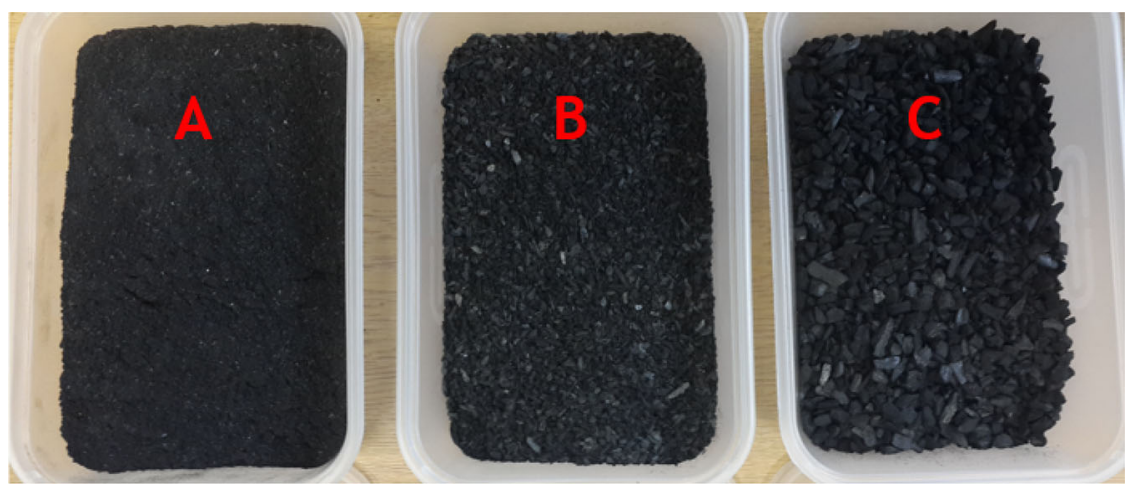

Fig. 4 The charcoal in three different sizes

\section{Experimental procedures}

The data collection of the experiment was conducted after thermal equilibrium in the reactor was reached. Therefore, initially, the hot air flow to heat up the reactor until the temperature at channel 1 achieve of about $400{ }^{\circ} \mathrm{C}$ (the coal ignition temperature) and their distribution became steady as indicated in the existing thermocouple. Then the packed bed of coal particles fed into the reactor for the reactions, and it was indicated by rapid increments in the sensor temperature initiated at channel 1 . The temperature changes in the sensor spot and gas products' concentration level were recorded. A picture of flame front propagation or ash formation can be captured through the optical access in sequences of time. However, almost during the test, the transparent lid was covered with an isolator (fire blanket) to minimise the heat loss through the lid.

The effects of particle sizes and the ignition temperatures on the coal particles gasification are investigated in the experiments. The test procedures are described in the section below.

\subsection{Test procedures to investigate the effects of particle size variation}

In the case of particle size variation, each coal, named A, $\mathrm{B}$, and $\mathrm{C}$, was packed and put on the bed of reactor. The experiment was performed in conditions without an additional heater in the rear side (the heat only from the hot air gas flow) and at the bottom side of the reactor well insulated. Schematic process of the test can be seen in Fig. 5.

Each coal was packed into a bed inside the reactor, and seven thermocouples arranged as in Fig. 5 in the middle of bed. The performance was identified through the pattern of temperature profiles. This experiment was performed for each coal size and with the same boundary conditions. The boundary condition of the test performance can be seen in Table 3.

\subsection{Test procedures to investigate the effects of temperature variation}

The second performance of the experiment was to investigate the effects of temperature variation. Here, an additional heater was supplied at the rear part of the coal packed bed area and this could be adjusted to control the temperature level. The schematic process of the test can be seen in Fig. 6.

The heater was controlled for several temperature conditions, and they were set at $135,200,275$ and $350{ }^{\circ} \mathrm{C}$, respectively. These tests initially were performed with coal $\mathrm{C}$, and an additional performance was used to confirm the behaviour with coal A and B. Figure 6 shows the additional heater position and channel 4 was used to monitor the temperature level of the heater (put at outside of reactor). The test was performed at an air flowrate of $2 \mathrm{slpm}$, with the variation of temperature level indicated in channel 4 . In a summary, the boundary condition of each test performance for temperature variation can be seen in Table 4 .

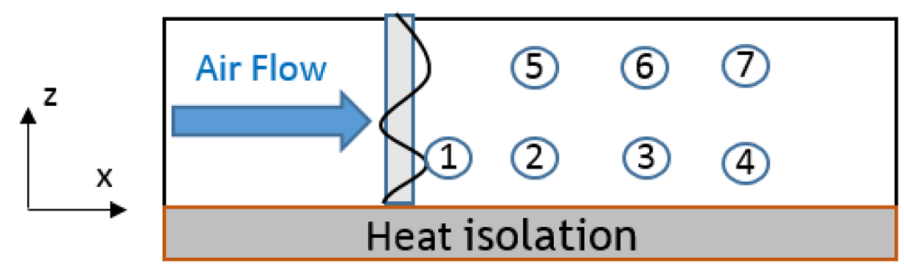

Fig. 5 Schematic process for particle size variation test from the side view 
Table 3 Boundary condition of test with particle size variation

\begin{tabular}{|c|c|c|c|}
\hline \multirow[t]{2}{*}{ Parameter } & \multicolumn{3}{|c|}{ Coal variation } \\
\hline & A & B & $\mathrm{C}$ \\
\hline Initial air temperature, $T_{1}\left({ }^{\circ} \mathrm{C}\right)$ & 400 & & \\
\hline Air flowrate variation (slpm) & $2-3.5$ & & \\
\hline Time of test performance (s) & 10000 & & \\
\hline External heater & No av & & \\
\hline
\end{tabular}

\section{Results and discussion}

\subsection{Investigation of the effects of particle size variation}

The temperature distribution in the coal bed for the reactions of coals A, B, and C can be seen in Fig. 7. This shows the pattern of temperature profile recorded by the thermocouples. The maximum temperature reached by each coal bed was $624{ }^{\circ} \mathrm{C}, 582{ }^{\circ} \mathrm{C}$, and $569^{\circ} \mathrm{C}$, for coals $\mathrm{A}, \mathrm{B}$, and $\mathrm{C}$, respectively. For this parameter, coal A had the highest bed temperature, while the lowest occurred with coal $\mathrm{C}$. This indicates that the bed with smaller particles obtained the higher temperature. The different particle size filling in the coal bed causes the difference in porosity of each packed bed (analogue to coal block). The smaller particle forms less porosity than the bigger particle size. The less porosity causes the heat transfer to take place more through the particle (conduction) than the porous material (convection). With the property of the heat capacity higher than gas, the particle reserves more heat than the gas. As a result, the coal bed with less porosity has a higher temperature than the bed with higher porosity.

From Fig. 7, it can also be seen that the temperature gradient (the temperature difference $\left(d_{T}\right)$ over the time $\left(d_{t}\right)$ ) of the bed with smaller particle size was higher-as can be seen in each channel of temperature measurement. The bed with coal $\mathrm{A}$ achieves the maximum temperature at channels 1, 2 and 5 earlier than the bed with coals B and C; and the bed with coal B was earlier than the bed with coal $\mathrm{C}$. Another indicator was the heat propagation rate, which can be identified by measuring the time interval of maximum
Table 4 Boundary conditions of test with temperature variation

\begin{tabular}{llllll}
\hline Parameter & \multicolumn{5}{l}{ Temperature variations $\left({ }^{\circ} \mathrm{C}\right)$} \\
\cline { 2 - 6 } & Heater off & 135 & 200 & 275 & 350 \\
\hline Coal A (with external heater) & $\sqrt{ }$ & & $\sqrt{ }$ & & $\sqrt{ }$ \\
Coal B (with external heater) & $\sqrt{ }$ & & $\sqrt{ }$ & $\sqrt{ }$ & $\sqrt{ }$ \\
Coal C (with external heater) & $\sqrt{ }$ & $\sqrt{ }$ & $\sqrt{ }$ & $\sqrt{ }$ & $\sqrt{ }$ \\
Initial air temperature, $T_{1}\left({ }^{\circ} \mathrm{C}\right)$ & 400 & & & & \\
Air flowrate (slpm) & 2 & & & & \\
Time of test performance $(\mathrm{s})$ & 4000 & & & & \\
\hline
\end{tabular}

$\sqrt{ }:$ The test conducted

temperature (peak temperature) between the two sensor temperature channels along the gas flow. One sample case was the time interval of heat propagation from channel $1-2$, at each coal bed. Figure 7 shows that the time needed for the heat to propagate (reach peak temperature) from channel 1-2 was $\sim 4600 \mathrm{~s}, \sim 4700 \mathrm{~s}$, and $8300 \mathrm{~s}$, for coal $\mathrm{A}, \mathrm{B}$ and $\mathrm{C}$, respectively. This indicates that heat propagation was faster in the bed with a smaller size of coal particle. Thus, this clarifies that the porosity coal block (in this test presented with the porosity of coal packed bed) has an important role in heat propagation in the coal block.

Visual observation can be used to evaluate and compare the gasification process under different operating conditions. Figure 8 illustrates the patterns of the coal particles packed bed at different times over the gasification procedures. The captures were taken from the top of the reactor or particle bed. This figure shows that the reaction process started with the same condition at minute zero. Over this time, the reaction fronts propagate and were indicated by the ash formation (white colour). The ash zone gets wider over the time of reactions in line with the gas flow direction. The final length of ash formation was compared for each coal after $180 \mathrm{~min}$. The results show that the distance was approximately $5 \mathrm{~cm}, 4.5 \mathrm{~cm}$ and $4 \mathrm{~cm}$ for the bed with coal $\mathrm{A}, \mathrm{B}$, and $\mathrm{C}$, respectively. This indicates that the smaller particle size has a longer distance from the inlet side of the coal bed. Therefore, the picture presented for observing the reactions' propagation was the surface area of the coal bed. This area has direct contact with the

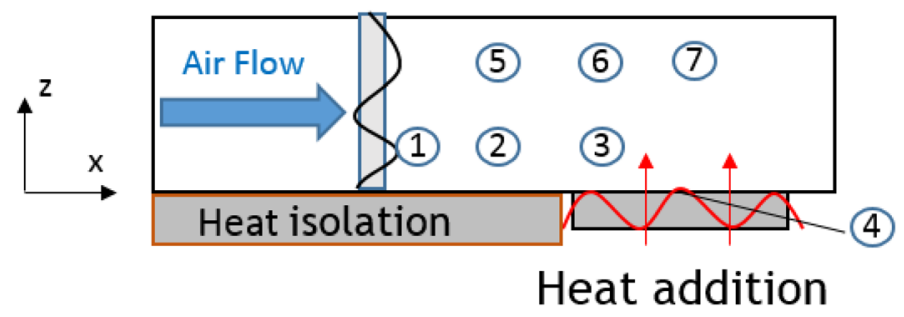

Fig. 6 Schematic process for temperature variation test from side view 

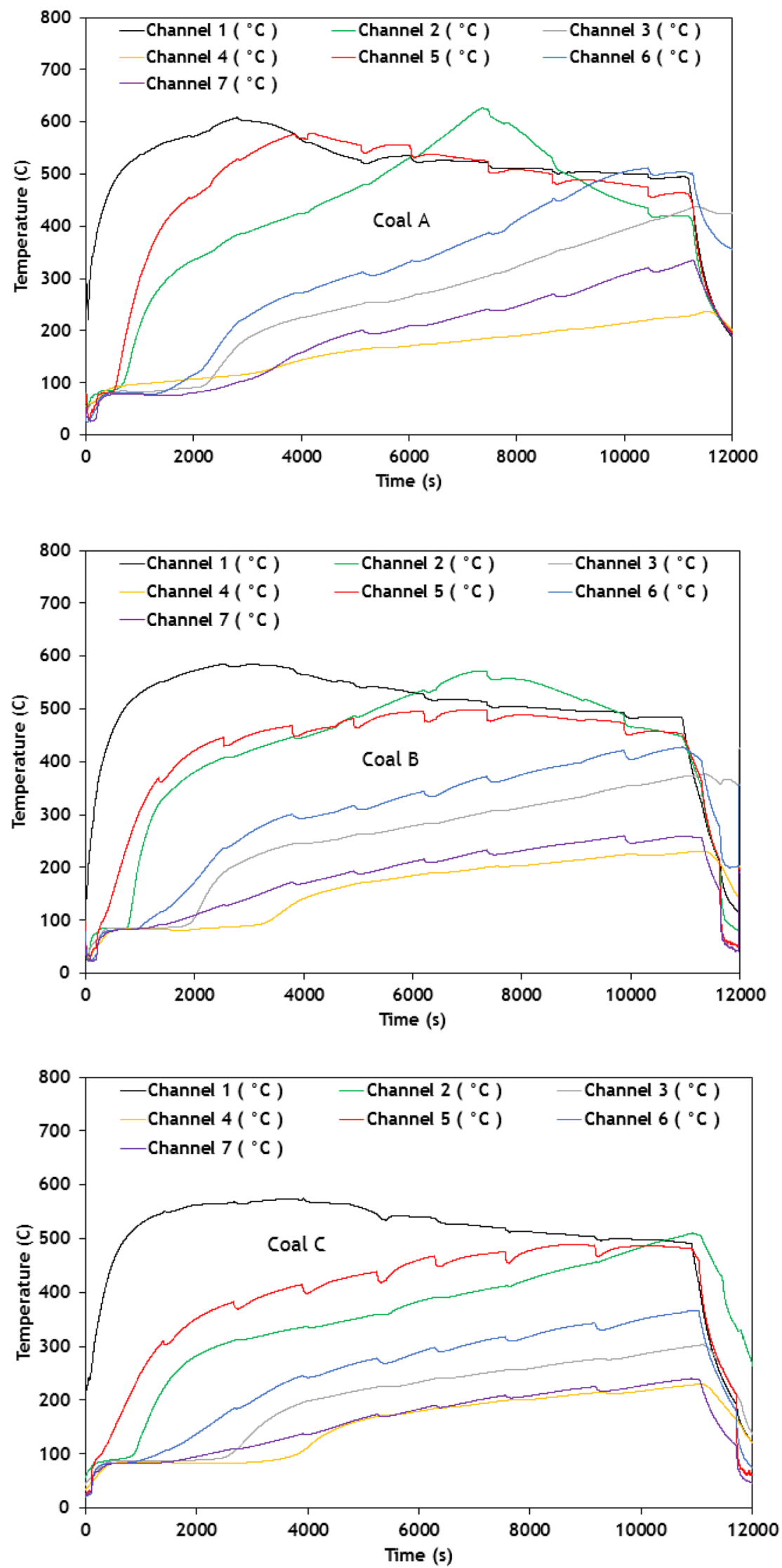
4Fig. 7 Temperature profile for each channel in bed of coals A, B and C

transparent lid and there was a gap between the coal bed surface and the lid. This notice was important in order to develop an understanding about the process observation of coal reactions.

The composition of gas products is an important index for the gasification process. As introduced in Sect. 2, four gas sensors were used to analysis $\mathrm{CO}_{2}, \mathrm{CO}, \mathrm{CH}_{4}$ and $\mathrm{O}_{2}$ in the exhaust during the experiments. The results of gas $\mathrm{CO}_{2}$, $\mathrm{CO}$ and $\mathrm{CH}_{4}$ from the gasification of coals $\mathrm{A}, \mathrm{B}$, and $\mathrm{C}$ are reported in Fig. 9. The experiments were performed for approximately $10,000 \mathrm{~s}(\sim 180 \mathrm{~min})$ at (temperature) and the mass flowrate of the injected air was increased gradually from 2 to $3.5 \mathrm{slpm}$.

Figure 9a illustrates the concentration of $\mathrm{CO}_{2}$ in the exhaust gas during the gasification process of coal $\mathrm{A}, \mathrm{B}$ and
$\mathrm{C}$, respectively. It can be clearly seen that, the different coal sizes has the amount and the trend for $\mathrm{CO}_{2}$ formation are almost the same during the process. The $\mathrm{CO}_{2}$ concentrations increase from the beginning when the reactions start. The growth lasts about for $30 \mathrm{~min}$ and then the concentrations become stable, which indicates the stability of the reactions.

The formation of $\mathrm{CO}$ in the gasification procedure is shown in Fig. 9b. Similar to that of $\mathrm{CO}_{2}$, at the initial stage, they increase and then remain nearly constant. However, the differences among coal $\mathrm{A}, \mathrm{B}$ and $\mathrm{C}$ are quite significant. It indicates that the concentration of $\mathrm{CO}$ is the lowest during the gasification of the coal packed bed formed by the smallest particle size A generates. The results of coal B and $\mathrm{C}$ are quite close, however the packed bed with larger size $\mathrm{C}$ has a greater value.

The gas production of $\mathrm{CH}_{4}$ reported in Fig. 9c has a different changing trend compared with that of $\mathrm{CO}_{2}$ and CO. It is shown that, they initially increase and then

$$
\mathrm{t}=0 \mathrm{~min}
$$
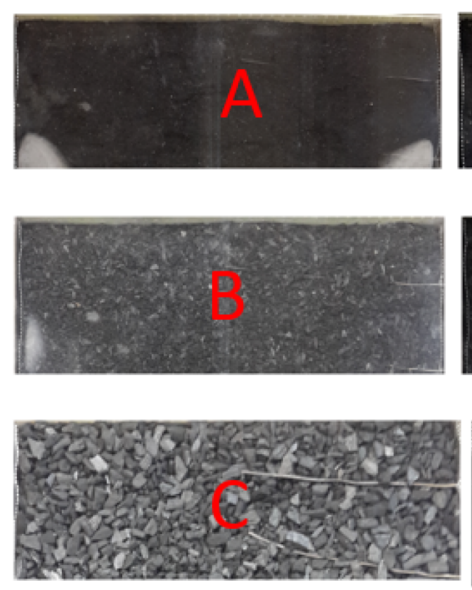

$$
\mathrm{t}=80 \mathrm{~min}
$$
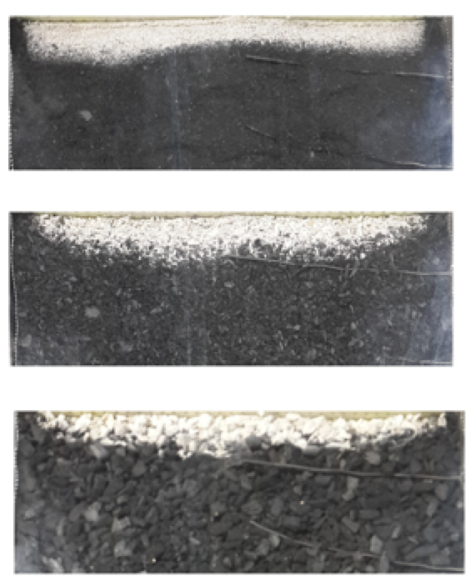

$\mathrm{t}=40 \mathrm{~min}$
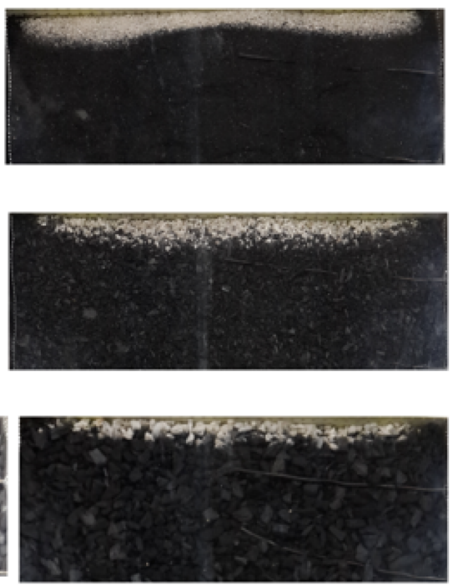

$\mathrm{t}=60 \mathrm{~min}$
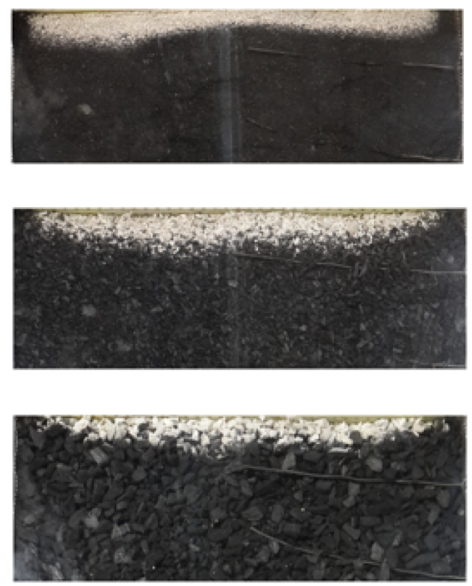
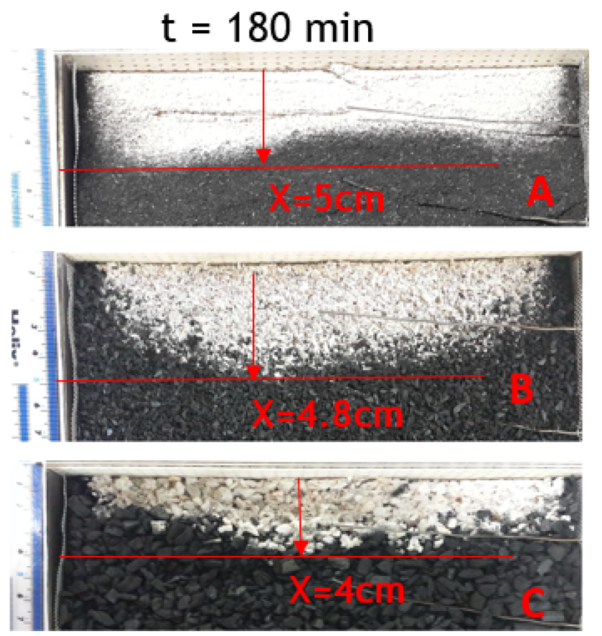

Fig. 8 The reaction propagation over a certain time period for coals A, B, and C 

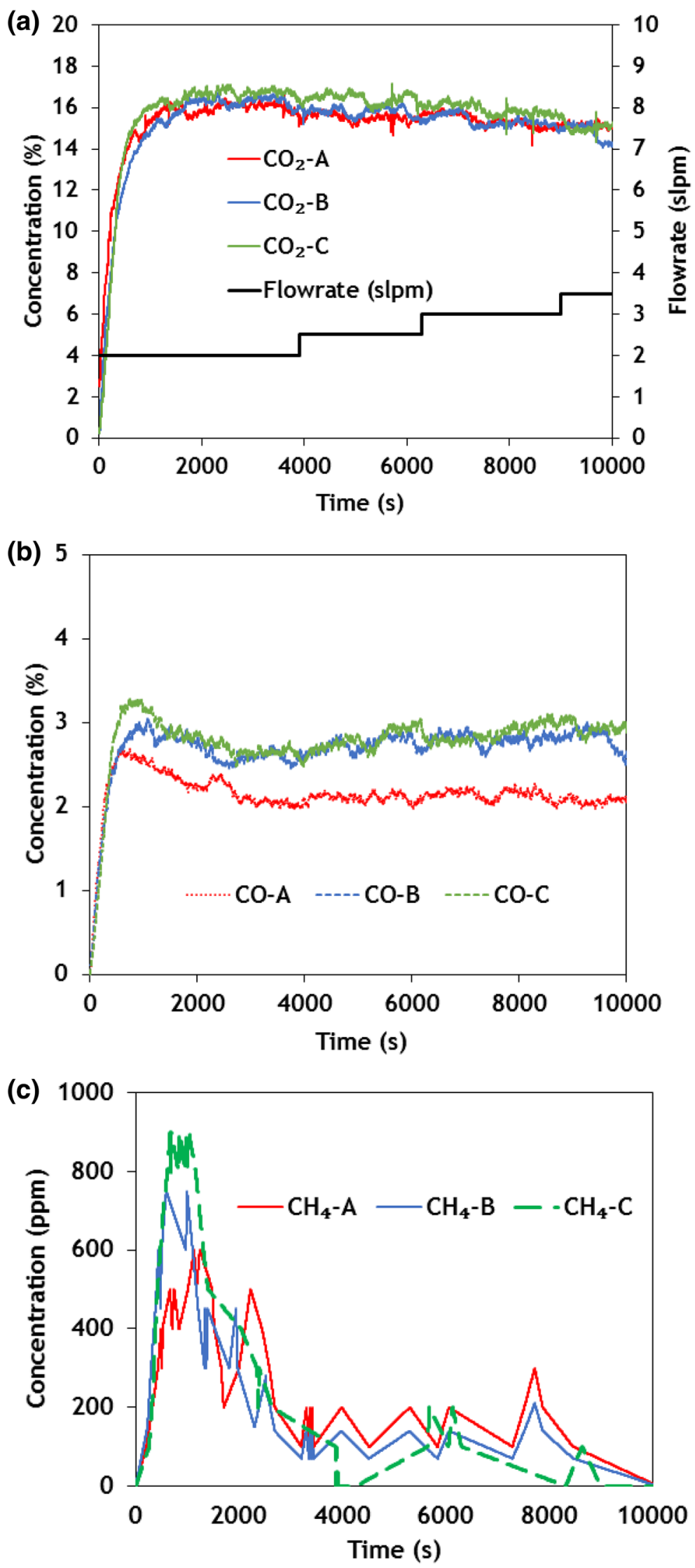
4Fig. 9 Gas products of coal bed reactions for $\mathbf{a ~} \mathrm{CO}_{2}$, b CO and $\mathbf{c} \mathrm{CH}_{4}$

decrease, after sometimes they finally dropped. This indicates an unstable supply of element to support of $\mathrm{CH}_{4}$ formation. The obtained results had a similar trend with the conditions of $\mathrm{CH}_{4}$ formation in the case of a single particle model (Sutardi 2019). However, Fig. 9 shows that the gas products $\left(\mathrm{CO}_{2}, \mathrm{CO}\right.$ and $\left.\mathrm{CH}_{4}\right)$ obtained higher value at packed bed with the bigger size of coal particle. These results need to be clarified to develop a strong understanding with the results shown in Figs. 7 and 8. It is provided after all measurement data observed.

The excess oxygen needs to be measured to find the correlation between the result of temperature and gas products. The measurement result is shown in Fig. 10. It can be found that the concentration of oxygen in the gas exhaust was slightly different from each test. The highest amount of oxygen obtained after the air went through and reacted with the packed bed formed by the smallest size coal A. This is consistent with the findings in Ref (Batenburg et al. 1994) where says the bed reactions with smaller coal size have more excess oxygen. This indicates that less oxygen reacts with charcoal, and therefore fewer products of $\mathrm{CO}_{2}$ and $\mathrm{CO}$ occurred in that case.

The packed bed piling with coal particles has different porosity when the particle size varies. The smaller particle size has the smaller the porosity of packed bed. In this study, the air flows through the porous packed bed to reacts with the coal surface and then produce the gas products. Therefore, the coal packed bed that has a smaller porosity where the air has less access to have the chemical reactions results in less gas products. The coal packed bed with a bigger porosity provides more space for the char and oxygen reactions to generate more products. This confirms the results obtained in Fig. 9 where there are the least gas products $\mathrm{CO}$ and $\mathrm{CO}_{2}$ and most excess oxygen in coal $\mathrm{A}$ experiment.

This looks slightly contradictory to the results explained in Figs. 8 and 9 about the effects of particle size on the reaction rate. It should be pointed out that the main factor causing the reaction propagation is the interaction between the coal and air. In theory, there are more air potentially reacts with coal if the porosity of the coal packed bed is greater. In the case taken from Fig. 8, the smaller particles exist on the surface of the coal bed and there was a gap between the bed and the transparent lid. This gap possibly provides more air on the surface, and therefore the heat propagation was faster in the smaller coal particle on this case.

\subsection{Investigation of the effects of temperature variation}

An investigation of the effect of temperature on the coal particle reactions that was performed in the modelling, now is continued through the experimental test. The aim is to identify the reaction behaviour by developing an understandable correlation between the modelling and the experiment. The experiments were conducted at three conditions: (1) external heater off, (2) external heater set at $200{ }^{\circ} \mathrm{C}$, (3) external heater set at $350{ }^{\circ} \mathrm{C}$. The mass flow rate of the injected air was $2 \mathrm{slpm}$. The test was conducted for $4000 \mathrm{~s}$ or about $60 \mathrm{~min}$ and the capture was taken every $15 \mathrm{~min}$.

Figure 11 shows the reaction front propagation identified with the ash products for coal A packed bed reactions. The initial results were shown at minute zero and, over time, the length of ash formed by the reaction got longer. After $60 \mathrm{~min}$, the distance between the inlet bed and the

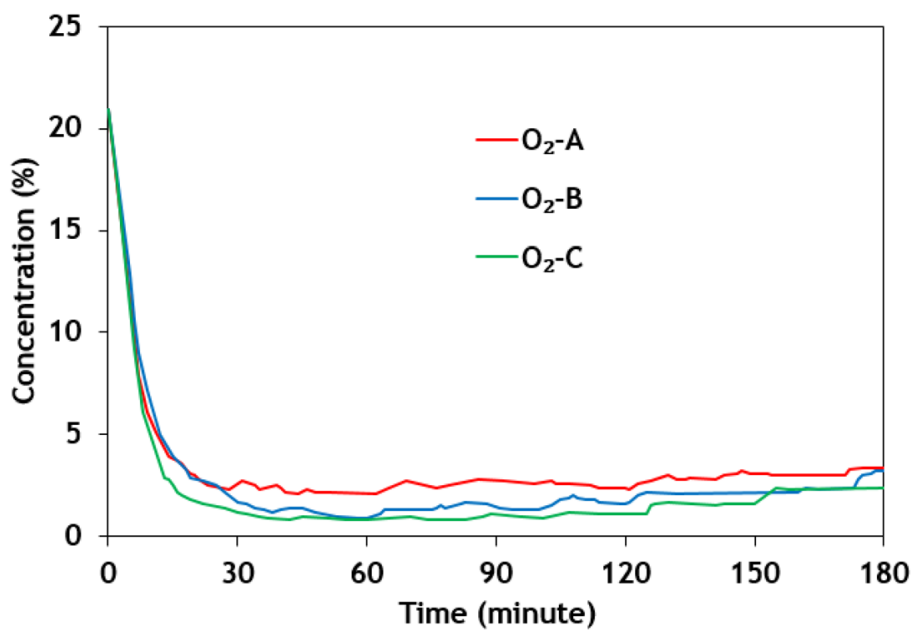

Fig. 10 Excess oxygen in gas products 

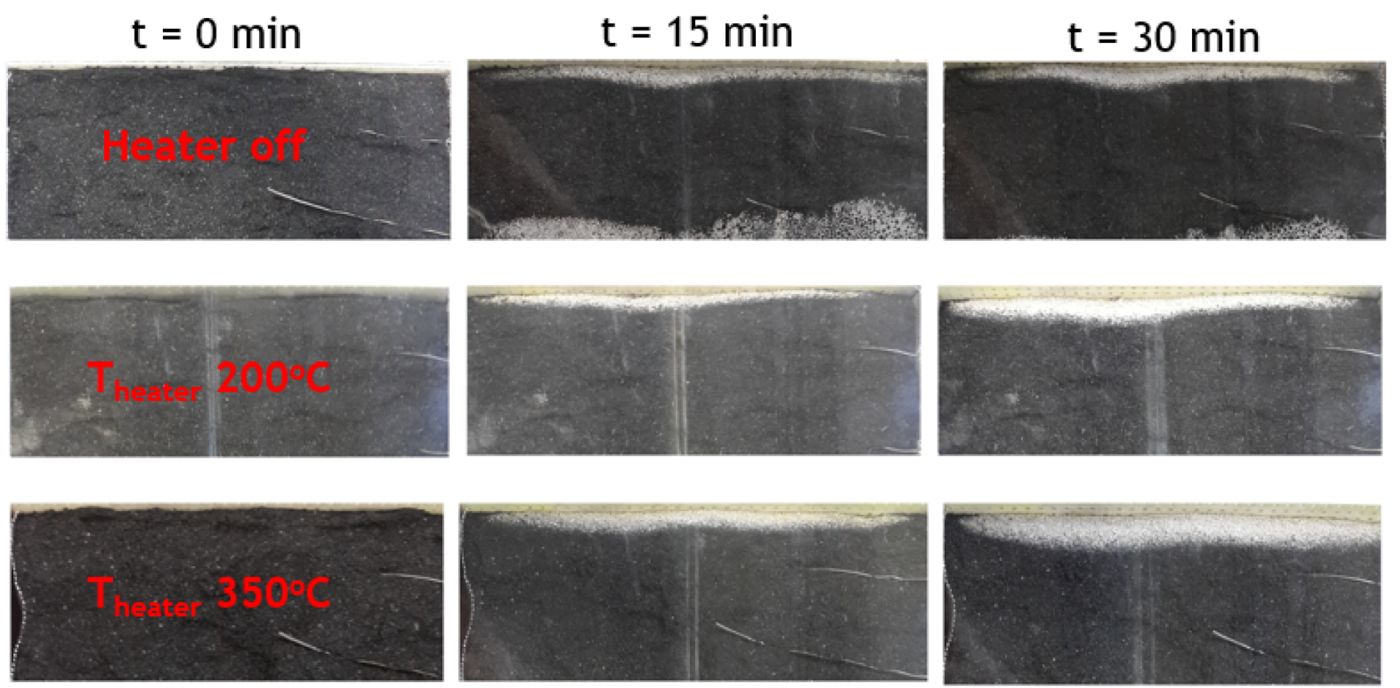

$\mathrm{t}=45 \mathrm{~min}$

$\mathrm{t}=60 \mathrm{~min}$
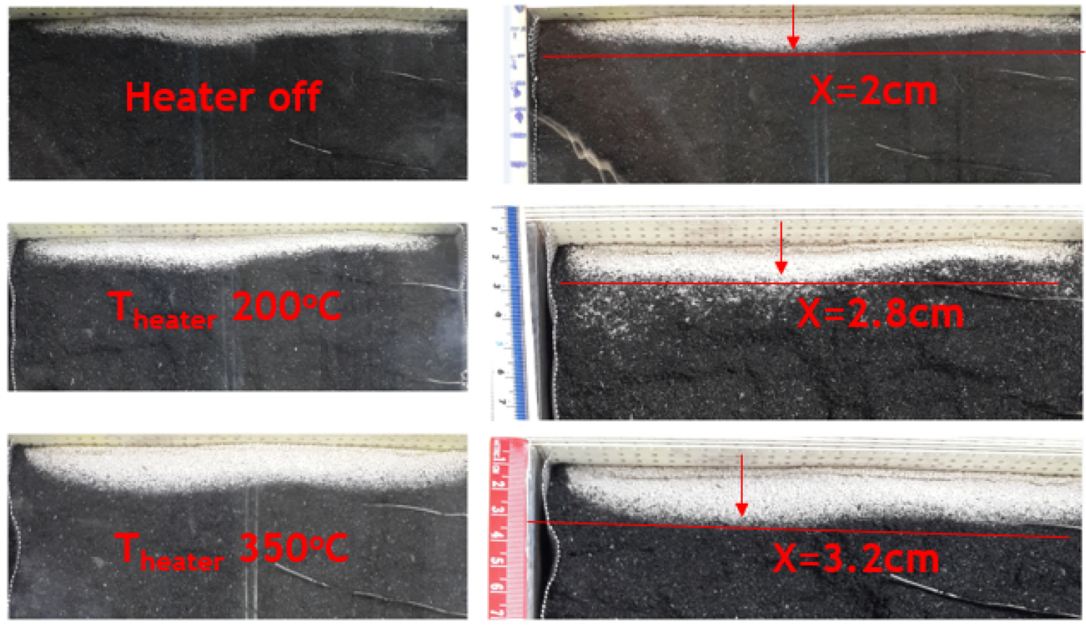

Fig. 11 Reaction front propagation of surface coal packed bed for coal A

boundary of coal and ash was measured. The maximum distances obtained were $2 \mathrm{~cm}, 2.8 \mathrm{~cm}$, and $3.2 \mathrm{~cm}$, for the condition of the heater at off, $200{ }^{\circ} \mathrm{C}$, and $350{ }^{\circ} \mathrm{C}$, respectively, as shown in Fig. 11. The result indicates that a particle bed with a higher temperature has a longer distance or a faster rate of reaction propagation. This is because with the same boundary condition the charcoal at higher reactor temperature will achieve their ignition temperature faster. The ignited charcoal produces heat and transfer to another spot, therefore the propagation of reaction front occurred faster.

The repetition scheme was conducted on the bed with coal B and C to confirm the results obtained. The same procedures, and boundary conditions were applied in Table 4. The pictures were captured on the test performance of coal A and B at the same time intervals under various temperatures and these can be seen in Figs. 11 and 12 , respectively.
Figure 12 presents the reaction front propagation presented with ash products on the bed with coal B. It has a similar trend to that of coal A. They were initiated at time zero and over time the length of ash formed by the reaction got longer. After $60 \mathrm{~min}$, the distance between the inlet bed and the boundary of reaction front was measured. It showed that the maximum distances were $1.9 \mathrm{~cm}, 2.6 \mathrm{~cm}$, and $2.8 \mathrm{~cm}$, for the temperature heater at off, $200^{\circ} \mathrm{C}$, and $275{ }^{\circ} \mathrm{C}$, respectively.

The reaction front propagation on the bed with coal $\mathrm{C}$ is reported on Fig. 13. The test performed, and the bed reactor was captured every $15 \mathrm{~min}$. After $60 \mathrm{~min}$, it showed that the maximum distances were $1.8 \mathrm{~cm}, 2.3 \mathrm{~cm}$, and $2.8 \mathrm{~cm}$, for the temperature of external heater at off, $200{ }^{\circ} \mathrm{C}$, and $350{ }^{\circ} \mathrm{C}$, respectively.

Figures 11,12 and 13 indicate that on the parameter of reaction front propagation, the coal $\mathrm{A}, \mathrm{B}$, and $\mathrm{C}$ have the same trend. The particle bed with the higher temperature 

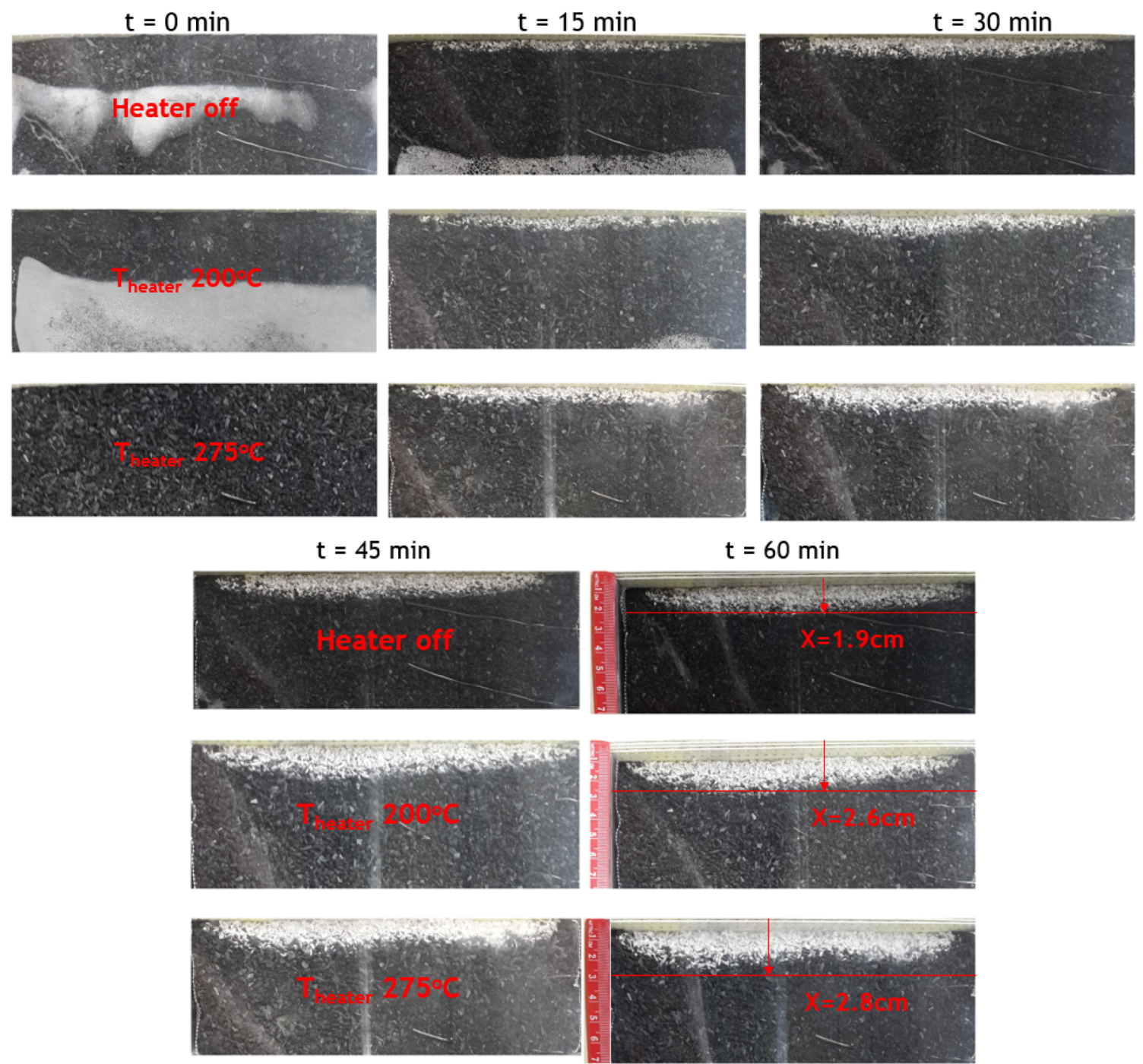

Fig. 12 Reaction front propagation of surface coal packed bed for coal B

has a longer distance of reaction front propagation. However, further observation can be conducted to identify the combination between coal particle size and temperature effect. At the same level of temperature heater set, for example at heater off, the length of reaction front propagation for coal $\mathrm{A}, \mathrm{B}$, and $\mathrm{C}$, were $2 \mathrm{~cm}, 1.9 \mathrm{~cm}$, and $1.8 \mathrm{~cm}$, respectively. And, when temperature heater set up to $275^{\circ} \mathrm{C}$, the length of reaction front for coal A, B, and C, were $2.8 \mathrm{~cm}, 2.6 \mathrm{~cm}$, and $2.3 \mathrm{~cm}$, respectively. All results identify that coal A had a maximum length of reaction front propagation compared with the results of coal B and $\mathrm{C}$, at the same level of temperature heater. And, coal B had greater of reaction front length than coal C. It again affirms of the effects coal particle size as described in Sect. 4.1.

The coal reaction behaviour was also investigated through the monitoring of gas products. The results of the measurement of gaseous $\mathrm{CO}_{2}, \mathrm{CO}$ and $\mathrm{CH}_{4}$ in the exhaust can be seen in Fig. 14. This figure shows the concentrations of these gas products during the coal $\mathrm{C}$ packed bed reactions at various heater temperatures. The test was performed at five different temperature levels in order to identify the effects. For gas products of $\mathrm{CO}_{2}$ and $\mathrm{CO}$, they had a similar trend. Initially they increase then become stable at some point, while $\mathrm{CH}_{4}$ had initially increased and then dropped. The gas $\mathrm{CH}_{4}$ dropped possibly caused by the lack supply of hydrogen element. However, all gas products indicated have more gas products at higher reactor temperatures.

More tests were conducted for coals A and B, but only at three temperature levels to confirm obtained results. The results for gas $\mathrm{CO}_{2}$ and $\mathrm{CO}$ can be seen in Figs. 15 and 16 for coals $\mathrm{A}$ and $\mathrm{B}$, respectively.

Figures 15 and 16 show a similar trend, during which they initially increase and stabilise after a certain period of time. The gas products' level was higher for the coal reactions at a higher temperature. Again, these results 

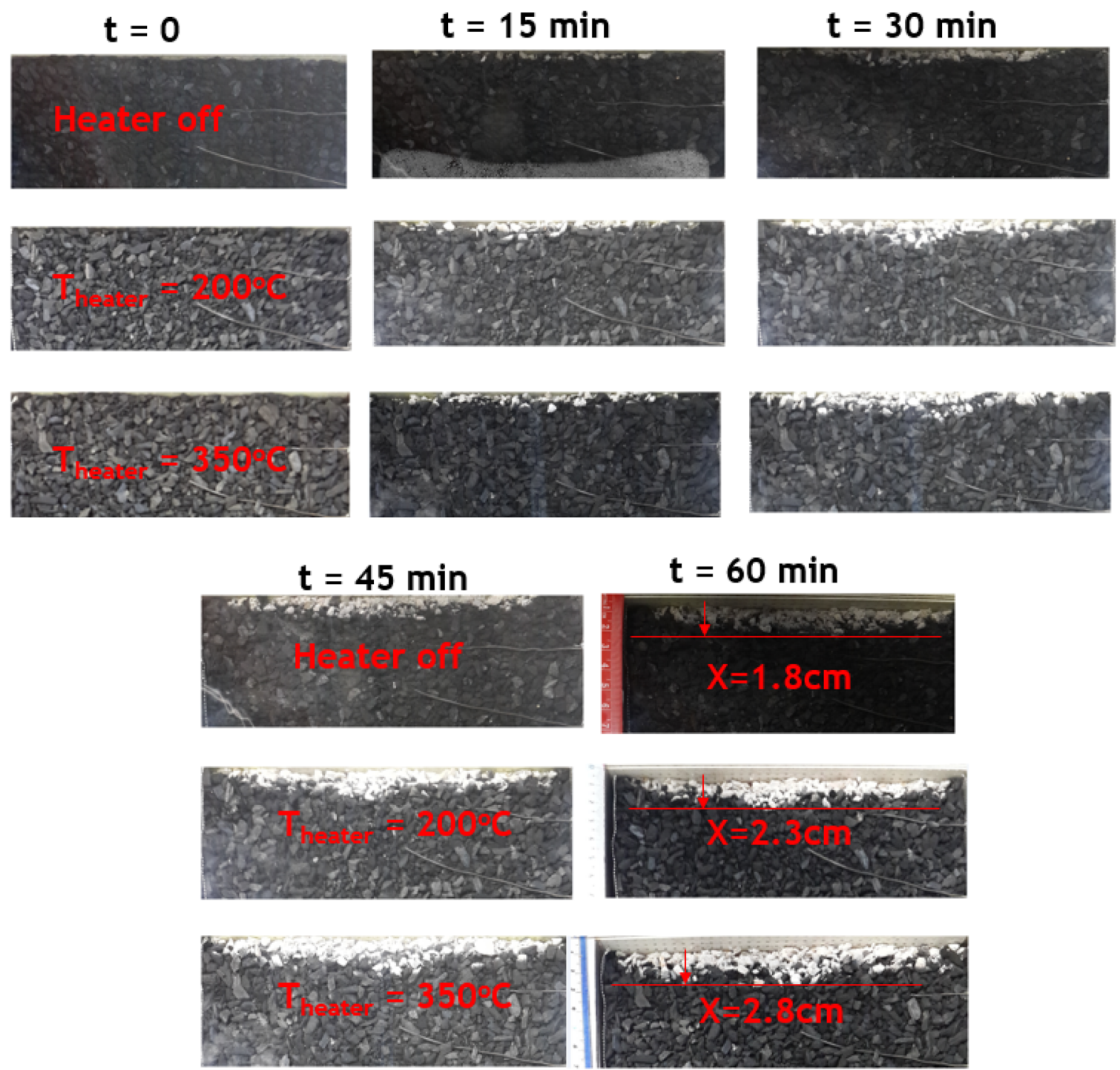

Fig. 13 Reaction propagation of surface coal packed bed for coal C

confirm the behaviour that the higher temperature could affect the coal reaction for producing more gas products.

However, the results of gas production in the experiments show a similar trend to the modelling in Ref (Sutardi et al. 2018b) simulation performance in various temperature. This was a good indication for an initial development of a coal particle model for gasification reactions.

\section{Analysis of results relevant with UCG application}

The experiment was developed with an aim to support the investigation of UCG with coal particle gasification model approach. There were some results can be considered in order to develop an understanding in UCG application.
The various particle size forms a different coal block porosity, in this test presented with the porosity of packed bed. The coal's pore, or porosity, is a parameter that influences the reactions in UCG application. It was stated by Wang et al. (2003) that the pores affect oxygen transport then participating in the chemical reactions during the oxidation process. The similar arguments also supported by Campbell (1978) and Merrick (1983), which stated the coal with more porous has a more permeable of a solid substance called char to be combusted and gasified by injected oxidant agents and exhausted gases from the previous steps. The pores itself can be formed during the drying and devolatilization process. At this stage, an inherent water and volatile matter content evolve their phase, and therefore the gasification agent replaces, flows through the pores. The behaviour caused by the effect of porosity to the coal reactions can be observed through the experimental. 

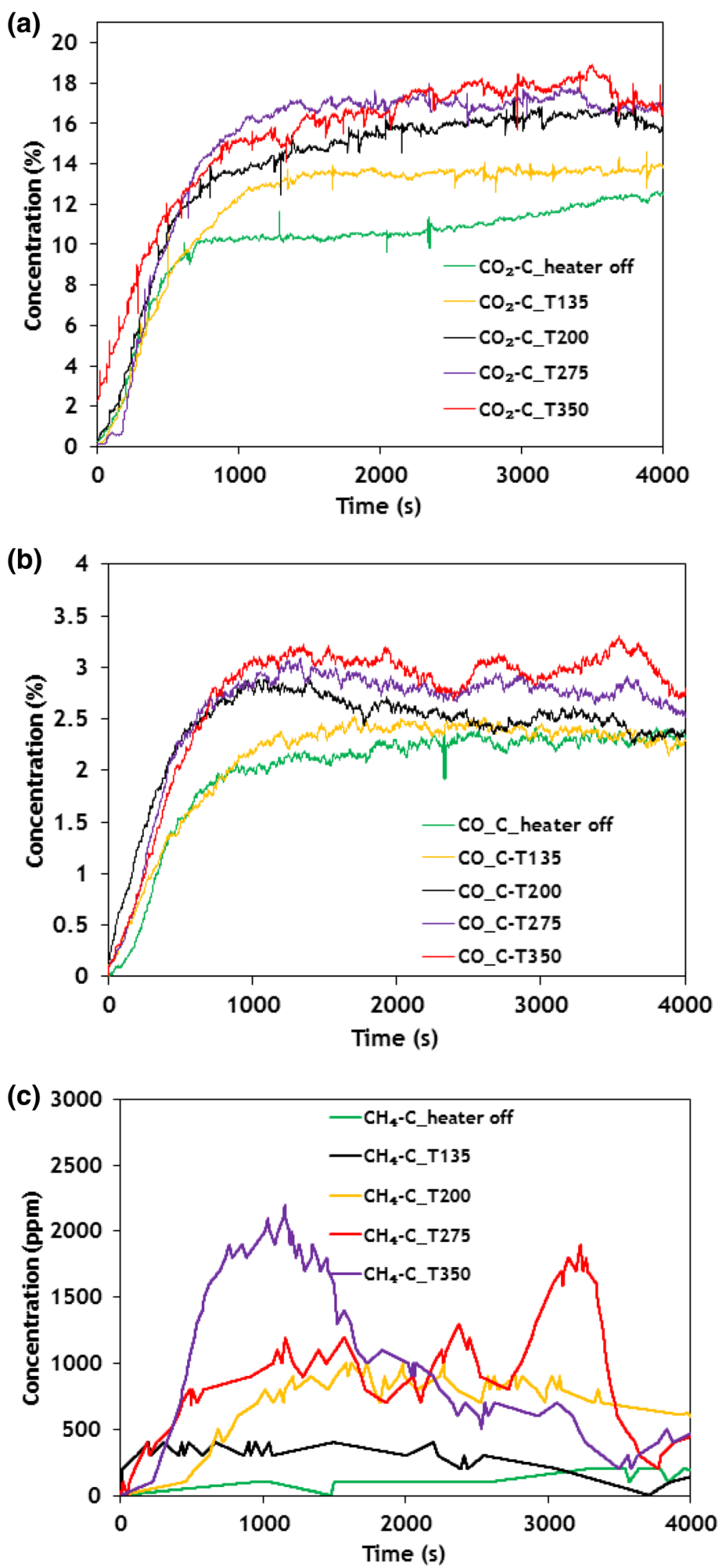

Fig. 14 Gas products of coal $\mathrm{C}$ in various temperature $\mathbf{a} \mathrm{CO}_{2}$, b $\mathrm{CO}$ and $\mathbf{c} \mathrm{CH}_{4}$ 

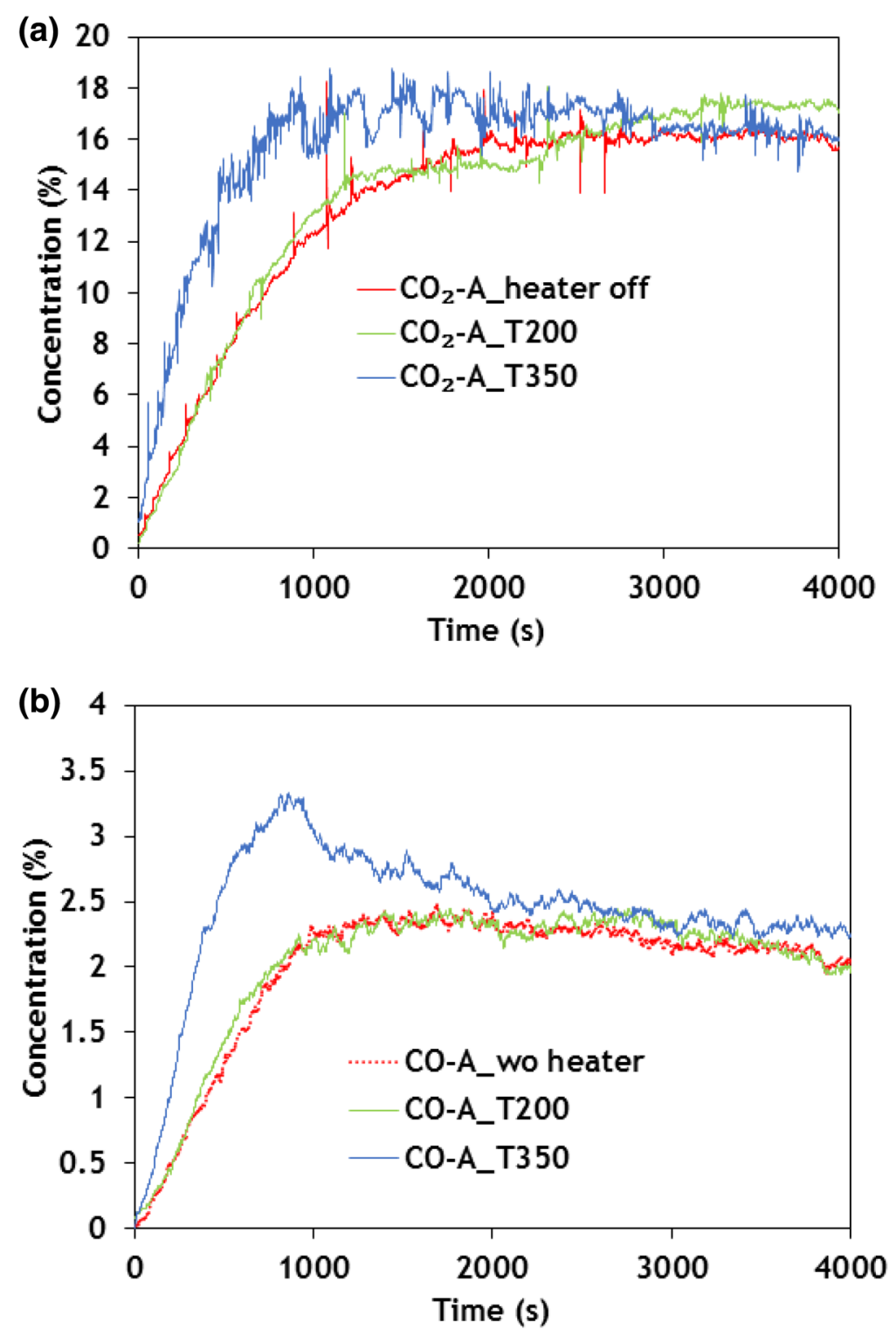

Fig. 15 Gas products of coal $\mathrm{A}$ at various temperatures $\mathbf{a} \mathrm{CO}_{2}$ and $\mathbf{b} \mathrm{CO}$

The particle size variations identify the different of coal porosity. It was obtained that the excess oxygen at the bed reactions with coal A was higher than coal B and C (see Fig. 10). It indicates that at the smaller porosity, the air and coal reactions occurred more at the channel surface. Meanwhile, the coal with greater pores could have more air reactions within the pores, and therefore their excess oxygen less. It also can be confirmed through the gas products (see Fig. 9), which showed that the $\mathrm{CO}$ and $\mathrm{CO}_{2}$ at coal $\mathrm{B}$ and $\mathrm{C}$ was higher than at coal $\mathrm{A}$, because of they had more porosity.

Temperature has an important role in the application of UCG. As stated by Yang (2008), the drop of temperature causes the decrease of $\mathrm{CO}$, and the increase of $\mathrm{CO}_{2}$. This behaviour potentially occurred in the reduction zone of gasification reactions. Of all reactions in the reduction zone, mostly were endothermic reactions. Especially at Boudouard reaction(Lahijani et al. 2015) that potential to convert the $\mathrm{CO}_{2}$ into $\mathrm{CO}$, as it preferable obtained in gasification process. Meanwhile, in the oxidation zone reactions, the increase of reactor temperature potentially increases both products, $\mathrm{CO}$ and $\mathrm{CO}_{2}$. This result is shown in the experimental with temperature variations, which indicates the more gas products $\left(\mathrm{CO}\right.$ and $\left.\mathrm{CO}_{2}\right)$ obtained at higher temperature. 

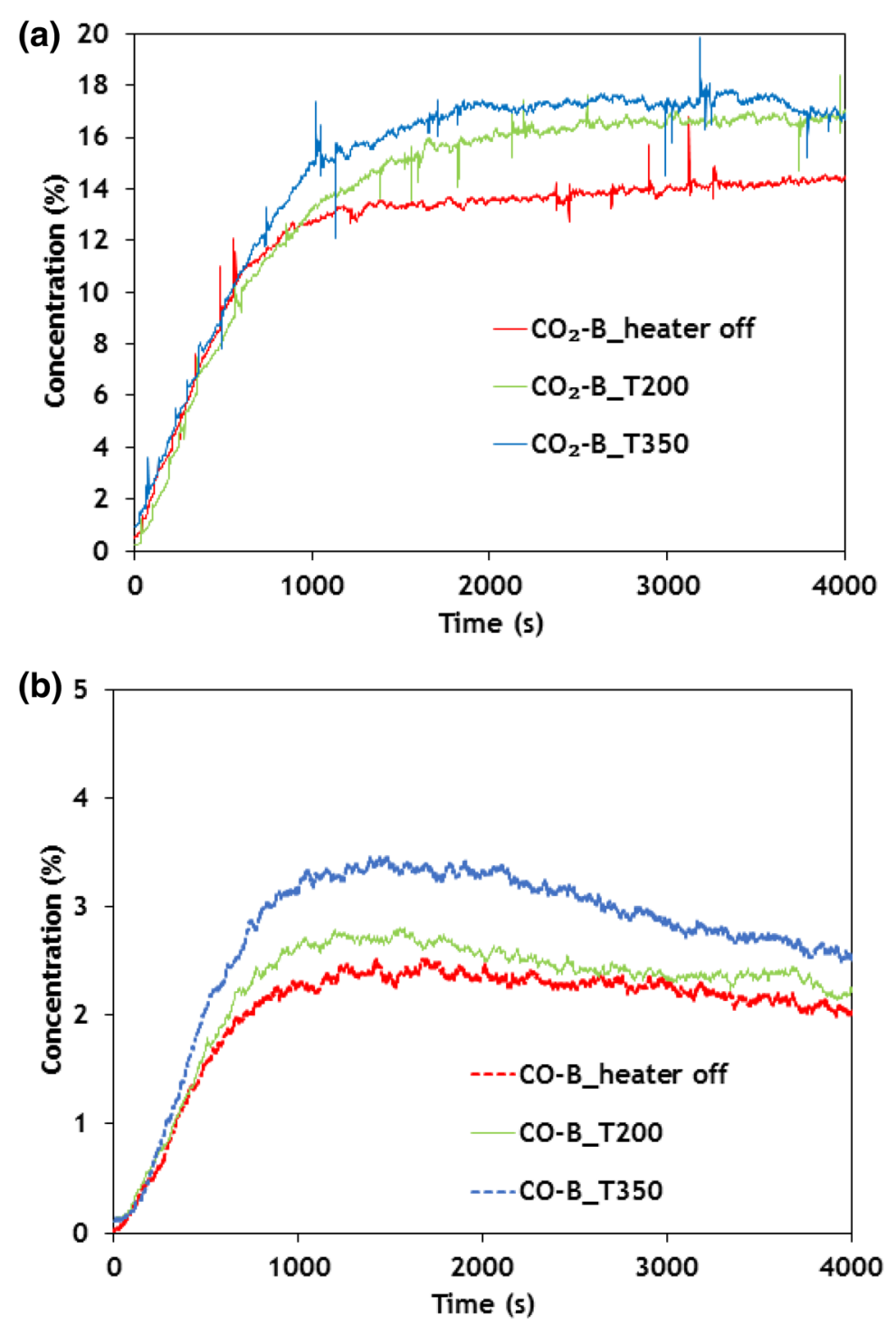

Fig. 16 Gas products of coal $\mathrm{B}$ at various temperatures $\mathbf{a} \mathrm{CO}_{2}$ and $\mathbf{b} \mathrm{CO}$

\section{Conclusions}

A coal particle packed bed reactor was developed for the experimental investigation of thermochemical reactions with varying coal samples and operating conditions. The investigation was conducted to correlate the findings of the model simulation of coal particle reactions performed earlier (Sutardi et al. 2018b; Sutardi 2019).

The study first related to the identification of the effect of particle size on the reactions. At the sufficient level of oxygen, the smaller coal particle size has a faster rate of reactions than the bigger size (Sutardi 2019; Surjosatyo and Nugroho 2013). However, when particles were packed to form a block, the porosity of the packed bed became a dominant factor during the gasification process. In the coal block, the appearance of porosity also helped the oxygen to access the greater area of the coal surface and thus promoted the reaction.

Secondly, the role of temperature of the coal reactions was investigated. The results of the experiment matched with those from the simulation model, and the higher temperature enhanced the reaction processes thus resulted in the increased amount of gas products.

Finally, even though, the experiment's performance was limiting in providing with the thermal energy to support the reactions in the rear side of the reactor (i.e. the reactions in the reduction zone), the current results sufficiently informed the crucial role and effect of temperature for the coal reactions.

Acknowledgements The first author gratefully acknowledges the Ministry of Research, Technology, and Higher Education (KEMENRISTEKDIKTI) of Republic Indonesia for the scholarship funding 
through the Research and Innovation in Science and Technology Project (RISET-Pro) program and also the University of Glasgow for supporting this research.

Open Access This article is licensed under a Creative Commons Attribution 4.0 International License, which permits use, sharing, adaptation, distribution and reproduction in any medium or format, as long as you give appropriate credit to the original author(s) and the source, provide a link to the Creative Commons licence, and indicate if changes were made. The images or other third party material in this article are included in the article's Creative Commons licence, unless indicated otherwise in a credit line to the material. If material is not included in the article's Creative Commons licence and your intended use is not permitted by statutory regulation or exceeds the permitted use, you will need to obtain permission directly from the copyright holder. To view a copy of this licence, visit http://creativecommons. org/licenses/by/4.0/.

\section{References}

Batenburg WD, Biezen NJ, Bruining J (1994) A new channel model for underground coal gasification of thin, deep coal seams. In Situ 18:419-451

Bhutto AW, Bazmi AA, Zahedi G (2013) Underground coal gasification: from fundamentals to applications. Prog Energy Combust 39:189-214

Campbell JH (1978) Pyrolysis of subbituminous coal in relation to in situ coal gasification. Fuel 57(4):217-224

Gregg DW, Edgar TG (1978) Underground coal gasification. AIChE J 24:753-781

Gunn RD (1977) Problem solved and problem not solved in UCG. Laramie energy research center, laramie, wyoming. Preprints of papers-American chemical society. Div Fuel Chem 22:64-75

Gunn RD, Krantz WB (1987) underground coal gasification: development of theory, laboratory experimentation, interpretation, \& correlation with the Hanna field tests. U.S. Department of Energy, Morgantown USA

Harish KRN, Udayakumar DL, Stojcevski A, Amanuallah MTO (2014) Underground coal gasification: an alternate economical and viable solution for future sustainability. Int J Eng Sci Invent 3:57-68

Higgins GH (1972) A new concept for in-situ coal gasification. Lawrence Livermore National Laboratory, Livermore

Khadse AN, Qayyumi M, Mahajani S, Aghalayam P (2006) Model for the underground coal gasification (UCG) channel reactor. Int $\mathrm{J}$ Chem React Eng 4:1-25

Khan M, Mmbaga J, Shirazi A, Trivedi J, Liu Q, Gupta R (2015) Modelling underground coal gasification-a review. Energies 8:12603-12668

Khatami R, Stivers Joshi K, Levendis YA, Sarofim AF (2012) Combustion behavior of single particles from three different coal ranks and from sugar cane bagasse in $\mathrm{O}_{2} / \mathrm{N}_{2}$ and $\mathrm{O}_{2} / \mathrm{CO}_{2}$ atmospheres. Combust Flame 159:1253-1271

Kuyper RA, Van der Meer TH, Bruining J (1996) Simulation of underground gasification of thin coal seams. In Situ 20:311-346

Lahijani P, Zainal ZA, Mohammadi M, Mohamed AR (2015) Conversion of the greenhouse gas $\mathrm{CO}_{2}$ to the fuel gas $\mathrm{CO}$ via the Boudouard reaction: a review. Renew Sust Energy Rev 41:615-632
Levendis YA, Joshi K, Khatami R, Sarofim AF (2011) Combustion behavior in air of single particles from three different coal ranks and from sugarcane bagasse. Combust Flame 158:452-465

Merrick D (1983) Mathematical models of the thermal decomposition of coal: 1. The evolution of volatile matter. Fuel 62(5):534-539

Sarraf Shirazi A, Karimipour S, Gupta R (2013) Numerical simulation and evaluation of cavity growth in in situ coal gasification. Ind Eng Chem Res 52:11712-11722

Sielke CW, Gorin E (1955) Kinetics of carbon gasification: interaction of hydrogen with low temperature char at 1500 to $1700 \mathrm{~F}$. Ind. Eng. Chem 47(4):820-825

Surjosatyo CA, Nugroho YS (2013) Predicting behavior of coal ignition in oxy-fuel combustion. Energy Procedia 37:1423-1434

Sutardi T (2019) The development of coal particle gasification model with application leading to underground coal gasification. Ph.D. Dessertation, University of Glasgow

Sutardi T, Paul MC, Karimi N, Younger PL (2017) Numerical study of the effects of $\mathrm{CO}_{2}$ addition in single coal particle gasification. Energy Procedia 142:1306-1311

Sutardi T, Paul MC, Karimi N (2018a) Investigation of coal particle gasification processes with application leading to underground coal gasification. Fuel 237:1186-1202

Sutardi T, Paul MC, Karimi N (2018) Numerical investigation on kinetic parameter of coal devolatilization reaction by identifying ignition delay parameter. In: Proceedings of the world congress on engineering and computer science San Francisco USA

Thorsness CB, Rosza RB (1976) In-situ coal gasification program: model calculations and laboratory experiments. Pet Eng J, Soc. https://doi.org/10.2118/6182-PA

Tsang THT (1980) Modeling of heat and mass transfer during coal block gasification. Ph.D. Dessertation, University of Texas at Austin

Uppal AA, Bhattib AI, Aamirb E, Samarb R, Khana SA (2014) Control oriented modeling and optimization of one dimensional packed bed model of underground coal gasification. J Process Control 24:269-277

Walker L (2007) Commercial development of underground coal gasification. Proc Inst Civ Eng (ICE) Energy 160(4):175-180

Wang H, Dlugogorski B, Kennedy E (2003) Coal oxidation at low temperatures: oxygen consumption, oxidation products, reaction mechanism and kinetic modelling. Prog Energy Combust 29(6):487-513

Wang LW, Karimi N, Sutardi T, Paul MC (2018) Numerical modelling of unsteady transport and entropy generation in oxycombustion of single coal particles with varying flow velocities and oxygen concentrations. Appl Therm Eng 144(5):147-164

Wang LW, Karimi N, Sutardi T, Paul MC (2019) Combustion characteristics and pollutant emissions in transient oxy-combustion of a single biomass particle: a numerical study. Energy Fuel 33:1556-1569

Winslow AM (1977) Numerical model of coal gasification in a packed bed. Proc Combust Inst 16(1):503-513

World Energy Council (2013) World energy resource-2013 Survey

Yang L (2008) A review of the factors influencing the physicochemical characteristics of underground coal gasification. Energy Sources Part A Recov Util Environ Effects 30(11):1038-1049

Yang D, Sheng Y, Green M (2014) UCG: where in the world. TCE Chem Eng 872:38-41 